\title{
COVID-19 y la bioseguridad en Latinoamérica. Retos y oportunidades
}

\section{COVID-19 Biosafety in Latin-America. Challenges and opportunities}

\author{
José Luis Sandoval-Gutiérrez*
}

*Instituto Nacional de Enfermedades Respiratorias Ismael Cosío Villegas. Ciudad de México, México.

Todo lo que el hombre puede ganar al juego de la peste y de la vida es el conocimiento y el recuerdo.

La peste, Albert Camus

A finales de diciembre de 2019 aparece en la ciudad de Wuhan en la provincia de Hubei en China ${ }^{1}$ un nuevo virus de transmisión aérea, el cual revoluciona las medidas del equipo de protección personal debido a los antecedentes de dos virus de la misma clase que ocasionaron el SARS y MERS que no evolucionaron a pandemia. Se observó con cierta cautela, pero no con la prevención debida (Figura 1).

A pesar de que Asia tuvo hace dos meses los primeros casos y la presentación se dio en esta área geográfica, nuestro continente actualmente es la región con más personas afectadas. La pregunta obligada es: ¿Qué hicimos mal?

Se sabe que hay varios factores que provocan la mayor dispersión de una pandemia:

- Alta densidad poblacional;

- Escaso acceso a servicios de salud;

- Población con enfermedades coexistentes (obesidad, hipertensión arterial, diabetes mellitus, etc.);

- Comunidad con factores de exposición importantes (contaminación, laboral, etc.);

Correspondencia:

Dr. José Luis Sandoval-Gutiérrez

Instituto Nacional de Enfermedades Respiratorias

Ismael Cosío Villegas, Ciudad de México, México.

Correo electrónico: sandovalgutierrez@gmail.com

Trabajo recibido: 01-VII-2020; aceptado: 18-VIII-2020.

Citar como: Sandoval-Gutiérrez JL. COVID-19 y la bioseguridad en Latinoamérica. Retos y oportunidades. Neumol Cir Torax. 2021; 80 (1): 9-10. https://dx.doi.org/10.35366/99448
- Falta de políticas públicas de prevención en materia de salud;

- Información imprecisa a nivel gubernamental;

- Red de laboratorios con heterogeneidad en controles de calidad;

- Poder adquisitivo limitado para nuevas tecnologías y/o medicamentos, entre otros.

Al parecer Latinoamérica cumple con varios o todos los puntos, según el país que se analice. Esta situación nos lleva a los siguientes retos:

- «Capacitación»

- «Capacitación»

- «Capacitación»

Tenemos el ejemplo de los Estados Unidos (EE.UU.), donde a pesar de ser la primera economía del mundo, su sistema de salud no mostró lo esperado para la contención necesaria al problema en boga. ${ }^{2}$

Nuestros países tienen las siguientes oportunidades:

- La información está disponible de forma gratuita y expedita.

- Nos une una misma lengua mayoritariamente desde la frontera con EE.UU. hasta el cono sur (aunque en Brasil no se habla español se entiende en gran parte), sin excluir a las regiones donde el inglés, francés y formas nativas de comunicación pueden participar en un mismo concepto.

- Hay un sentimiento de fraternidad entre naciones, no existe hasta el momento algún conflicto armado entre las mismas.

- Hay grupos de científicos y profesionales, aunque reducido en número, que dominan aspectos de 


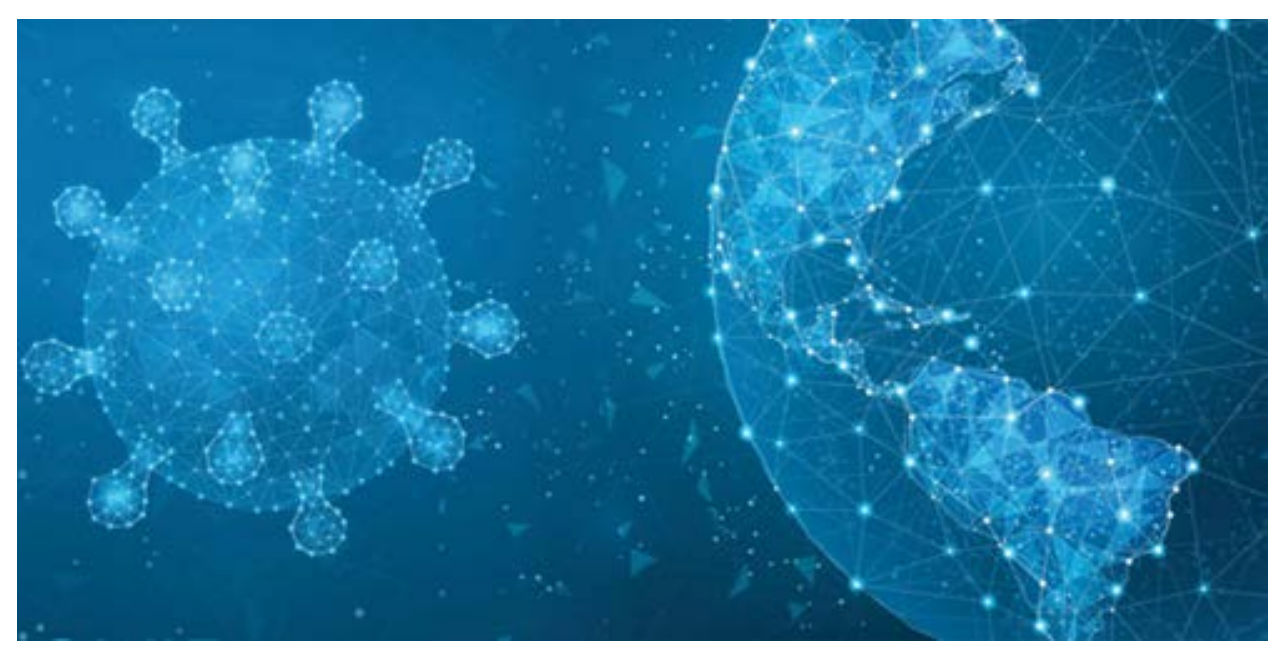

Figura 1:

Bioseguridad del COVID-19 en situación regional (Latinoamérica). Tomada de: https://www.wilsoncenter. org/article/covid-19-latin-america. bioseguridad/biocustodia, que son excesivamente entusiastas en difusión y promoción del conocimiento existente. $^{3}$

- Se cuenta con las alianzas académicas y colaboración con las principales asociaciones en estos tópicos, además de interrelación laboral e investigación con las agencias de salud en el orbe.

- La mayoría de los sistemas de salud son públicos con organización centralizada, lo que permite un canal de comunicación específico.

- Aunque limitados, existen recursos económicos (la mayoría de las naciones en Latinoamérica son de ingresos medios) ${ }^{4}$ para solventar las necesidades iniciales de insumos materiales y tecnológicos.

- La vecindad con EE.UU. y Canadá nos convierte en un polo estratégico desde el punto de vista de la geopolítica.
Con todo lo anterior sólo resta mencionar: Bioseguricemos a Latinoamérica

\section{REFERENCIAS}

1. WHO Coronavirus disease (COVID-19) dashboard. [Access date 2020 Jun 29] Available from: https://covid19.who.int/

2. Casos en los EE. UU. [Access date 2020 Jun 29] Available from: https://espanol.cdc.gov/coronavirus/2019-ncov/cases-updates/casesin-us.html

3. Asociación Mexicana de Bioseguridad A.C. [Fecha de consulta 30 de junio de 2020] Disponible en: http://amexbio.org/

4. América Latina y el Caribe. [Fecha de consulta 01 de julio de 2020] Disponible en: https://datos.bancomundial.org/region/america-latinay-el-caribe

Conflicto de intereses: El autor declara no tener conflicto de intereses. 